\section{COURRIER}

\section{Les chemins du non-soi}

Le «stress» verrouille à différents niveaux la réponse immunitaire, mais la finalité évolutive d'un tel phénomène n'est pas claire.

Aussi, peut-on se demander : «Que se passerait-il si ce mécanisme physiologique ne se mettait pas en jeu ? " La réponse à cette question peut entraîner la réflexion très loin. Ce mécanisme existe pour éviter un vieillissement accéléré (déjà en 1979, Walford avait proposé "the immunology theory of aging "). Le vieillissement peut être spécifique d'organe ou plus diffus et résulte de l'interaction du système immunitaire avec le système d'expression du «soi »; le complexe majeur d'histocompatibilité (CMH).

Par ailleurs, on sait, depuis les travaux de J.L. Strominger et Don

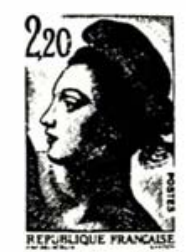

Wiley, de Harvard, que le site antigénique des molécules HLA (A2 en l'occurrence) n'est pas vide, mais présente des peptides qui expriment peut-être le soi cellulaire. Ainsi, peut-on faire émerger un concept nouveau, celui du soi évolutif dans lequel la présentation de peptides est le support de l'évolution du soi.

Dans un tel concept, l'émotion, le stress représentent des «moteurs » évolutifs, la tolérance immunitaire correspond à une rééducation permanente des cellules $T$, l'autoimmunité résulte d'une pathologie du «verrouillage » donc du vieillissement.

Le système immunitaire ne peut plus être vécu comme un simple système de défense car force nous est d'admettre que nous portons en nous les germes de notre propre destruction; mais ne cachons pas notre admiration pour cette nature empreinte d'une dualité subtile, qui associe les mécanismes nécessaires à la vie comme à la mort.

Le débat dans ces colonnes est maintenant ouvert.

Dr J.-M. de Sède Les Graviers I Avanne-Aveney 25720 Beure

\title{
L'avenir de la santé de l'homme se trouve-t-il aux champs?
}

Personne ne doute des vertus pour notre santé d'une existence campagnarde... mais ce n'est pas à cela que fait référence le titre de cette lettre. Les champs dont je veux parler ici sont utilisés pour cultiver des plantes nouvelles, aux propriétés étranges qui pourraient bien modifier en profondeur nos conceptions actuelles sur les dangers et les perspectives des «biotechnologies » de nouvelle génération, celles utilisant la recombinaison génétique. Les résultats positifs de création de plantes transgéniques sont maintenant très nombreux et s'étendent à des espèces d'intérêt agroalimentaire majeur: tomate, colza, pommes de terre, riz, maïs... etc. Les nouveaux gènes ajoutés au patrimoine héréditaire des plantes peuvent en améliorer la valeur nutritive (en augmentant la synthèse d'une vitamine ou d'un acide aminé limitant), la productivité et la résistance à des conditions climatiques défavorables (sécheresse, notamment, voire chaleur ou froid), la résistance à des maladies végétales et à l'agression par divers parasites, insectes, champignons ou autres. En ce sens, il est possible d'espérer que seront ainsi produites des espèces qui ne nécessiteront pas l'épandage de ces pesticides si peu satisfaisants aux plans de l'écologie, et parfois, de la santé publique. Une ambition majeure des biologistes moléculaires végétaux, de réalisation probablement encore lointaine, est de conférer aux espèces qui en sont dépourvues (les céréales, par exemple), la propriété de fixer l'azote de l'air, et donc de pouvoir se développer en l'absence d'engrais azotés. Quand on sait que, d'une part, l'insuffisance dans la disponibilité en ces engrais est une des causes des très faibles productivités agricoles de nombreux pays et, qu'à l'inverse et d'autre part, l'utilisation massive de ces substances dans les pays riches joue un rôle certain dans l'appauvrissement de l'atmosphère en ozone, on mesure l'importance de l'enjeu! Oui, vraiment, encadrée et maîtrisée avec lucidité et prudence, la biotechnologie végétale moderne s'apparente, par certains de ses aspects, à un grand combat écologique.

Mais ce n'est pas tout : les plantes sont des organismes eucaryotes à croissance rapide et peu exigeantes. L'idée est donc venue à certains, notamment la compagnie belge Plant Genetics System (PGS) de les utiliser à la place des microorganismes (bactéries, levures) ou des cellules animales pour produire des substances d'intérêt biologique : insuline, interleukines, fac- teur antihémophilique, vaccins... etc. Les plantes comme le colza possèdent des organes de réserve dans lesquels s'accumulent de très grandes quantités de certaines protéines. Il devrait donc être possible de «cibler » l'expression active de gènes codant pour des substances d'intérêt vers ces organes, utilisant pour cela les promoteurs et régions de contrôle des gènes végétaux dirigeant l'accumulation de ces protéines de réserve. Demain, l'alimentation et les médicaments viendront-ils des cultures de nos campagnes? Nos agriculteurs «feront-ils» quelques hectares de maïs, d'orge, de luzerne... plus un peu d'insuline ou d'hormone de croissance? Si l'évolution est bien cellelà, nos industries pharmaceutiques auront à faire face à de nouveaux problèmes de fractionnement, la séparation complète de la substance d'intérêt des composants végétaux pouvant se révéler ardue : de nouveaux débouchés en perspective pour nos étudiants s'ils se forment à ces techniques de purification protéique ou peptidique.

Docteur Axel KAHN, Président de la Commission du Génie Biomoléculaire auprès du Ministre de l'Agriculture et de la Forêt. 